\title{
Differences Among Self-Esteem in a Nationally Representative Sample of 15-17-Year-Old Omani Adolescents
}

\author{
Kashef Zayed \\ Sultan Qaboos University, \\ Muscat, Oman \\ Badriya Al-Haddabi \\ Sultan Qaboos University, Muscat, Oman \\ Lakshmanan Jeyaseelan \\ Christian Medical College, \\ Vellore, India \\ Mansour Al Tauqi \\ Sultan Qaboos Youth Complex for Culture \& Intertanmen, Salala, Oman \\ Mostafa Wally \\ Sultan Qaboos University, Muscat, Oman \\ Samir Al-Adawi \\ Sultan Qaboos University, \\ Muscat, Oman \\ Majid Al-Busafi \\ Sultan Qaboos University, Muscat, Oman \\ Nasser Al-Rawahi \\ Qatar University, Doha, Qatar \\ Fathi Thiyabat \\ King Fahad University, Dhahran, Kingdom of Saudi Arabia

\begin{abstract}
This study aimed to understand the association between self-esteem (SE) and gender, age, body mass index (BMI) and rural-urban dichotomy among Omani teenagers. Multivariable regression analyses were conducted using generalized linear models to study the impact of gender, age, BMI, and place of residence on the SE score after adjusting for other variables. Of the 4,432 teenagers studied, $47.4 \%$ were boys and $52.6 \%$ girls. The majority (64.4\%) were from rural areas and 35.6\% from urban areas of Oman. About 23\% were physically underweight, while $51 \%$ were normal and $26.2 \%$ were overweight or obese. The results of this study revealed that Omani girls have higher SE than boys. It also showed that no relationship between SE and BMI. Finally, the results showed that children residing in rural areas had higher SE than those in city dweller.
\end{abstract}

Keywords: SE, BMI, gender differences, adolescents

Kashef Zayed, Ph.D., Associate Professor, Department of Physical Education \& Sports Sciences, Sultan Qaboos University, Muscat, Oman.

Lakshmanan Jeyaseelan, Ph.D., Professor, Department of Biostatistics, Christian Medical College, Vellore, India.

Samir Al-Adawi, Ph.D., Professor, Department of Behavioural Medicine, College of Medicine and Health Sciences, Sultan Qaboos University, Muscat, Oman.

Badriya Al-Haddabi, Ph.D., Associate Professor, Department of Physical Education \& Sports Sciences, Sultan Qaboos University, Muscat, Oman.

Majid Al-Busafi, Ph.D., Associate Professor, Department of Physical Education \& Sports Sciences, Sultan Qaboos University, Muscat, Oman.

Mansour Al Tauqi, Ph.D., General Manager, Sultan Qaboos Youth Complex for Culture \& Intertanmen, Salala, Oman.

Nasser Al-Rawahi, Ph.D., Physical Education Program, College of Education, Qatar University, Doha, Qatar.

Mostafa Wally, Ph.D., Associate Professor, Department of Nutrition \& Food Sciences, Sultan Qaboos University, Muscat, Oman.

Fathi Thiyabat, Ph.D., Associate Professor, Schools Supervisor, King Fahad University, Dhahran, Kingdom of Saudi Arabia. 


\section{Introduction}

The health and living standards in the Arabian Gulf State of Oman have improved dramatically in the recent decades due to rapid growth in healthcare infrastructure, and the country's UNDP Human Development Index, at 0.796, is classified "high" (United Nations Development Programme, 2016). Life expectancy in Oman has reached 77.1 years (Goujon, Weber, \& Loichinger, 2016). The fertility rate for Omani women, which was the third highest in the world at 8.3 in 1980, dwindled to 2.7 in 2014 and is trending lower (Goujon, Weber, \& Loichinger, 2016). The process of acculturation and globalization were similarly fast-tracked in Oman, facilitated by near $100 \%$ school enrolment, the resultant high literacy (94\%), internet penetration (66.5\%), and the ubiquitous presence of a very large expatriate population (45\%) (Khan \& Fernandez-Carag, 2016).

The most visible change in Oman is reflected in its current demographic structure, which is pyramidal and youth-heavy (World Bank, 2017). Omani society is going through the crucial "second phase" of "demography in transition" (Omran, 2005), which, according to Corruccini and Kaul (1983) is characterized by baby boom, youth bulge, and plasticity of longevity. In Omani society there has been an increase in lifestyle and environment-related health problems including signs of unprecedented levels of psychological distress (Al-Adawi, 2006b).

History of humanity has been rife with stressful periods characterized by dramatic changes in lifestyle and demography (Nettleton, 2013). Such periods were evolutionary battlegrounds where the fittest survived. Modern Arab societies (along with the rest of the developing world) seem to be passing through a similar period of change (Mulder, 1998). Fortunately, unlike in the past, we have tools to monitor change and develop interventions to help the survival of not only the fit, but also the relatively unfit.

Teenagers form vulnerable age-group during periods of social change (Berry, Phinney, Sam, \& Vedder, 2006), and thus the warrant further studies. Adolescence is the period where one's childhood sense of self is gradually replaced by a new, more independent self-image (Damon \& Hart, 1982). Self-esteem (SE) is an important emotional and cognitive state that has direct bearing on the young person's sense of well-being, which in turn nourishes their maturing adult self-image (Robins, Trzesniewski, Tracy, Gosling, \& Potter, 2002). Thus measuring adolescents' SE can serve as an indicator of their self-image, which in turn could be predictive of their future psychosocial functioning. Various schools of psychology have suggested that SE is an important engine for eventual self-actualization (Robins et al., 2002; Taormina \& Gao, 2013), love for self, and others (Fromm, 1939). Conversely, a low SE is associated with less vicissitude to cope with stress and distress (Lee, Kim, Kim, \& Park, 2016; Gooding et al., 2015).

However, various studies have shown the universality of the concept of SE (Damon \& Hart, 1982; Robins et al., 2002). Some studies are dissenting to such view (Heine, Lehman, Markus, \& Kitayama, 1999; Choi \& Choi, 2016) while others have found that the concept has heuristic value across different societies and linguistic groups (Schmitt \& Allik, 2005). As the cultural patterning differs from society to society, it is likely that sociocultural and ecological factors play a substantial role in the expression of SE. While the pan-universalism of the concept of SE has yet to be established, one fruitful approach to assess the heuristic value of SE is to examine its correlates such as gender, anthropometric factors, and rural-urban dichotomy.

Various studies have examined the relationship between SE and chronological age. Robins et al. (2002) have examined age differences in SE from childhood to old age via internet research among US population (N $=326,641)$. The study asserts that SE is high among American children, plummets during adolescence, rises 
again during adulthood, and declines during old age. Other studies from different populations have also concluded similarly (Hudson \& Fraley, 2016; Ogihara, Uchida, \& Kusumi, 2016; Bleidorn et al., 2016). However, there is a dearth of studies on SE and age from the Arabic speaking populations.

As regards the relationship between gender and SE, Abdel-Khalek, Korayem, and El-Nayal (2012) strongly indicated that Arab female college students may have lower SE than males. This appears to be a worldwide phenomenon, as shown by a large cross-cultural study of the indices of SE in 985,937 internet users, from late adolescence to middle adulthood, spread across 48 nations of the world (Bleidorn et al., 2016). That study also reported significant gender gaps, with males endorsing higher SE than females. Another study examined self-esteem adolescents' girls found that self-esteem positively correlated to educational status of the rural girls (Akande, 1993). While previous studies in the Arab world that examine the gender gap in SE offer valuable information, they have generally focused on late adolescents, that is, college going population (Abdel-Khalek, Korayem, \& El-Nayal, 2012). There is a lack of studies examining the relationship between gender, age, body weight, place of residency, and SE among young adolescents, that is, school-going population, in Arabic-speaking populations of Oman.

One of the trajectories of SE and gender is the observation that females tend to be more dissatisfied with their external appearance which might negatively affect their SE in comparison to the male counterparts (Furnham, Badmin, \& Sneade, 2002). In Arabic-speaking populations, there is a traditional preference for a voluptuous form. However, recent shifts in dietary habits have triggered an upsurge of obesity (Musaiger, 2004) which, in turn, has been associated with the rising tide of restrictive food intake and other measures to reduce increasing obesity (Musaiger et al., 2013). One fallout of such trend is the increasing number of youngsters in the Arabic speaking countries resorting to undertake deliberate food intake restriction so they could lower their body mass index (BMI) (Kayano et al., 2008; Al-Adawi et al., 2002). Previous studies have examined the relationship between BMI and SE (Konttinen et al., 2014; International Conference on Challenges of Urbanization in GCC Countries, 2014), but there are no such studies have been forthcoming from the Arabic speaking population. Studies are therefore warranted that examined the link between body image vis-a-vis body mass index and SE.

In developing countries like Oman, urban-rural dichotomy is increasing (International Conference on Challenges of Urbanization in GCC Countries, 2014). As modern Oman appears to be highly urbanized, it would be instructive to examine the difference in SE between urban and rural dwellers. Various studies have indicated that emotional distress related to SE differs between rural and urban settings (Peen, Schoevers, Beekman, \& Dekker, 2010). There is dearth of study on relationship between SE and urban-rural setting among adolescent populations. This study, therefore, has embarked to explore three interrelated themes. The first is to examine the gender-related differences in SE. The secondly is to explore to explore the relationship between SE and BMI and third is to examine the relationship between SE and place of residence.

\section{Method}

\section{Participants}

The study was conducted during the period from 24 September 2015 to 9 May 2016 in all the 11 governorates in the Sultanate of Oman. Oman has 11 governorates (Muscat, Al Batinah North, Al Batinah South, Al Buraimi, Ad Dakhiliyah, Ash Sharqiyah North, Ash Sharqiyah South, Dhofar, and Musandam) with an estimate of four million Omani nationals (Sambidge, 2014). The sample used in the current study has been 
selected to represent all the 11 Omani governorates. The bulk of the population is concentrated in the north and the south. These two regions are separated by the intrusion of the "Empty Quarter" or Rub' al Khali of the Arabian Peninsula. The major part of this distribution occurs in the north along the coastal strip of the Gulf of Oman.

\section{Selection of a Nationally Representative Sample}

According to statistics available from the Ministry of Education (2017), in the academic year 2015/2016 there were 85,771 pupils in the country enrolled in Grades 10 and 11 in public schools (which are schools run by the state under the direction of the Ministry of Education). A school-based random cluster sampling was used to select the representative school. Seventy-one public schools were selected from among 819 public secondary schools in Oman. All Grade 10-11 students from the selected schools were invited to participate in the study during the academic year 2015/2016. The sample size of 4,528 was intended to be nearly $5 \%$ of a total of 85,771 students enrolled in 10 and 11 grades in all schools in Oman. We coordinated with the Ministry of Education to select the targeted schools and to facilitate our mission of collecting the data. After excluding the incomplete and/or non-clear questionnaires that were returned, the net study sample comprised 4,432 participants $(2,102$ boys and 2,330 girls) proportionately representing the target population in all Omani provinces.

All students were given invitation letters addressed to their parents/guardians describing the rationale for the study. The parents/guardians were asked to sign consent forms if they consented to their wards' participation. In addition to receiving parental consent, the pupils were also required to give consent before taking part in the study. In brief, the pupils were explicitly assured that their participation was anonymous and voluntary, that the data gathered would be aggregated, and that they could withdraw from the study at any time, without prejudice. In the event that undue distress was experienced by the pupil while responding to sensitive questions, counselling support was offered if needed. The pupils were also asked not to discuss the questions among themselves in order to avoid peer influence.

\section{Variables Assessed}

Self-esteem (SE). The Rosenberg Self-Esteem Scale (RSES) was used to quantify the variation of SE (Rosenberg, 1965). RSES is a 10-item self-report questionnaire. All items answered on a Likert four point scale ranging from strongly disagree and strongly agree. The scale includes five negative items that need to be reversed before calculating the sum of the total scores, so the higher scores indicating higher SE. RSES has been demonstrated to have good validity and reliability across many different samples (Piyavhatkul et al., 2011) including Arabic-Speaking populations (Aldaqal \& Sehlo, 2013; Al-Fayez, Ohaeri, \& Gado, 2012).

Body mass index (BMI). Weight and height were measured during the study using standardised procedures (Cole, Bellizzi, Flegal, \& Dietz, 2000). In brief, body weight was measured to a nearest $\mathrm{cm}$ in a standing position without wearing shoes. Waist circumference (WC) was measured using a non-stretched measuring tape to the nearest $\mathrm{cm}$ at naval level. Calibrated Body Composition Analyzer (TANITA) was used to measure weight and BMI as detained elsewhere (Kutáč, 2015). For the present purpose, the variation of BMI was classified as follows: Underweight $\leq 18.5$, Normal Range $=18.5-23$, Overweight and Obese $>25$.

Urban-rural dichotomy. For brevity, the governorates closer to the capital were classified as urban (e.g., Muscat, Al Batinah North, Al Batinah South) while the rest were deemed to be rural (e.g., Al Buraimi, Ad Dakhiliyah, Ash Sharqiyah North, Ash Sharqiyah South, Dhofar, and Musandam). 


\section{Statistical Methods}

The summative score of the SE instrument was obtained and it followed nearly the normal distribution. As bivariate analyses student T-test and Analysis of Variance (ANOVA) were conducted to compare the mean (SD) of SE score between groups. Multivariable regression analyses were done using generalized linear model to study the impact of study variables on the SE score after adjusting for other variables. Statistical significance was fixed at $\mathrm{p}<0.05$ level. SPSS 21.0 was used to analyse data.

\section{Results}

The distribution of sociodemographic variables and BMI is presented in Table 1. Of the 4,432 adolescents studied $47.4 \%$ were boys and $52.6 \%$ girls. Fifteen-year-olds comprised $18.1 \%$ of the sample while 16 and 17 year-olds were $36 \%$ and $45.9 \%$ respectively. Most (64.4\%) participants were living in rural areas and $35.6 \%$ in urban areas. About $23 \%$ of the participants were found to be underweight, $51 \%$ normal and $26.2 \%$ overweight or obese.

The mean (SD) of each item in the self-esteem (SE) instrument is presented in Table 2. All the items in the instrument had a mean (SD) of about 2 (1) units. The mean responses were consistent for all items. The overall mean (SD) SE score was about 20 (6).

Table 3 presents the correlation among sociodemographic variables, BMI, and SE score. As in the bivariate analyses the female subjects had $1.7(1.3,2.0)$ units significantly higher SE score as compared to male subjects after adjusting for other variables $(\mathrm{p}<0.001)$. Rural area subjects had $1.5(1.1,1.9)$ units significantly higher SE score compared to urban area subjects $(\mathrm{p}<0.001)$. Fifteen years old subjects had $-1.0(-1.50,-0.51)$, units significantly lower SE score as compared to 17 years old subjects $(\mathrm{p}<0.001)$. However, 16 years old had $0.3(-0.06,0.7)$, units higher SE score as compared to age 17 years $(p=0.09)$. However, BMI was not significantly correlated with SE score.

Table 1

Distribution of Sociodemographic Variables and Body Mass Index (BMI) Among National Representative Sample of School Going Children (15-17 Years Old Students) in Oman (2015-2016)

\begin{tabular}{llll}
\hline Sociodemographic variables & & $\mathrm{N}$ & $\%$ \\
\hline \multirow{2}{*}{ Gender } & Male & 2,102 & 47.4 \\
& Female & 2,330 & 52.6 \\
\hline \multirow{3}{*}{ Age (years) } & 15 & 8,00 & 18.1 \\
& 16 & 1,596 & 36.0 \\
\hline \multirow{2}{*}{ BMI } & 17 & 2,036 & 45.9 \\
& Underweight (BMI $\leq 18.5)$ & 1,014 & 22.9 \\
$*$ Place of residence & Healthy weight (BMI = 18.5-23) & 2,258 & 50.9 \\
& Over weight and obesity (BMI $\geq 25)$ & 1,160 & 26.2 \\
\hline
\end{tabular}

Notes. * Urban (Muscat, Al Batinah North, Al Batinah South); Rural (Al Buraimi, Ad Dakhiliyah, Ash Sharqiyah North, Ash Sharqiyah South, Dhofar, and Musandam). 
Table 2

Mean (SD) of Items of Self-Esteem Instrument Among National Representative Sample of School Going Children (15-17 Years Old Students) in Oman (2015-2016)

\begin{tabular}{llll}
\hline & Item & Mean & SD \\
\hline 1 & I feel that I am a person of worth, at least on an equal plane with others. & 2.38 & 0.70 \\
2 & I feel that I have a number of good qualities. & 2.28 & 0.81 \\
3 & All in all, I am inclined to feel that I am a failure. & 2.07 & 0.82 \\
4 & I am able to do things as well as most other people. & 2.03 & 0.78 \\
5 & I feel I do not have much to be proud of. & 1.91 & 0.99 \\
6 & I take a positive attitude toward myself. & 2.08 & 0.82 \\
7 & On the whole, I am satisfied with myself. & 2.27 & 0.85 \\
8 & I wish I could have more respect for myself. & 1.13 & 1.09 \\
9 & I certainly feel useless at times. & 2.19 & 0.82 \\
10 & At times, I think I am no good at all. & 1.93 & 0.98 \\
& Total Self-Esteem & 19.9 & 6.12 \\
\hline
\end{tabular}

Table 3

Correlation Between Self-Esteem and Sociodemographic Variables and Body Mass Index Among National Representative Sample of 15-17 Year-Old Students in Oman (2015-2016)

\begin{tabular}{|c|c|c|c|c|c|c|}
\hline \multirow[b]{2}{*}{ Variables } & \multicolumn{3}{|c|}{ Bivariate } & \multicolumn{3}{|c|}{ Multivariable } \\
\hline & $\mathrm{N}$ & Mean (SD) & p-value & $\begin{array}{l}\text { Regression } \\
\text { Coefficient }\end{array}$ & $95 \% \mathrm{CI}$ & p-value \\
\hline \multicolumn{7}{|l|}{ Gender: } \\
\hline Male & 2,102 & $19.04(6.02)$ & \multirow{2}{*}{$<0.001$} & Ref. & & \\
\hline Female & 2,330 & $20.67(6.12)$ & & 1.69 & $1.34,2.05$ & $<0.001$ \\
\hline \multicolumn{7}{|l|}{ Age: } \\
\hline 15 & 800 & $19.11(6.26)$ & \multirow{3}{*}{$<0.001$} & -1.003 & \multirow{4}{*}{$\begin{array}{l}-1.50,-0.51 \\
-0.055,0.733\end{array}$} & \multirow{3}{*}{$\begin{array}{l}<0.001 \\
0.09\end{array}$} \\
\hline 16 & 1,596 & $20.26(6.12)$ & & 0.339 & & \\
\hline 17 & 2,036 & $19.92(6.12)$ & & Ref. & & \\
\hline \multicolumn{6}{|l|}{ Body mass index: } & \\
\hline Healthy weight & 2,258 & $19.88(6.13)$ & \multirow{4}{*}{0.438} & Ref. & \multirow{4}{*}{$\begin{array}{l}-0.37,0.52 \\
-0.27,0.58\end{array}$} & \multirow{4}{*}{$\begin{array}{l}0.737 \\
0.475\end{array}$} \\
\hline Underweight & 1,014 & $19.74(6.01)$ & & 0.077 & & \\
\hline Overweight/obese & 1,160 & $20.07(6.19)$ & & 0.155 & & \\
\hline Place of residence** & & & & & & \\
\hline Urban & 1,579 & $18.98(6.21)$ & \multirow{2}{*}{$<0.001$} & Ref. & & \\
\hline Rural & 2,853 & $20.42(6.01)$ & & 1.50 & $1.13,1.87$ & $<0.001$ \\
\hline
\end{tabular}

\section{Discussion}

To our knowledge, this is the first study that examined the relationship between self-esteem (SE) and gender, body mass index and rural-rural dichotomy among a representative sample of 15-17 years old students in Oman. SE is an interesting concept. Low SE is often equated with poor self-concept and has been correlated with risk behaviour and mental health problem (Baumeister, Campbell, Krueger, \& Vohs, 2003). In contrast, high SE have postulated to resonate self-confident and resoluteness to encounter challenges of life and tribulations (Baumeister et al., 2003).

The first aim of this study is to explore the gender difference and SE. The present study suggests that 15-17 year-old Omani girls endorse significantly higher SE scores compared to boys. Higher scores signify better or higher SE. Our results are thus different from those of other studies where the indices of SE across 48 
nations were found to be higher in males (Bleidorn et al., 2016). In one meta-analysis, Kling, Hyde, Showers, and Buswell (2009) acknowledged the higher SE scores of males in but pointed out that this may vary according to socioeconomic, sociodemographic, gender-equality, and cultural value indicators of a society (Bleidorn et al., 2016). Relevant for the present study, gender difference in SE was noted to be less pronounced in societies in transition (Zuckerman, Li, \& Hall, 2016). Omani society is in the process of transition from traditional to modernity. Female empowerment appears to be one of fallout of the modernization and acculturation in Oman (Al-Lamki, 2002). It is possible, therefore higher esteem of females in Oman arises due to changing social orders. Another factor that may have contributed to this finding is that females academic performance is better than that of males (Islam, 2014) and this can have an impact on their self-esteem as many studies have found that academic status is related to self-esteem (e.g., Nagar, Sharma, \& Chopra, 2008).

The related aim of the represent study was to examine the relationship between age and SE. In a systematic review, Zuckerman, Li, and Hall (2016), minor different between gender and SE was noted and such trend tended to peak during adolescence and declined upon the onset of adulthood. In support of such view, although the age group of the present cohort was limited 15-17 years old, the study nevertheless suggests that age has direct bearing on SE. Previous studies have focused on the differences among children, adolescence, and adult (Robins et al., 2002; Bleidorn et al., 2016). There is dearth of study on SE and age from the Arabic speaking population. This study suggests that even with teenagers there are complex and significant fluctuations in relationship between age in SE.

On one hand, in traditional Omani society, the preference for "voluptuous" female figure (which indicates fertility) has been so much that girls are sometimes force fed to reach that ideal (Popenoe, 2012; Al-Adawi, Jaju, Al-Zakwani \& Dorvlo, 2011). On the other hand, Omani youth are also under the influence of "the cult of thinness" reinforced by the media (Hesse-Biber \& Am I, 1996) or obesogenic behaviours characterized by sedentary lifestyle but complemented by adopting to fat and calorie rich dietary habits (Malik, Willett, \& Hu, 2013), traditional standard of beauty appears to have eroded as testified with increasing numbers of youngsters resorting to drastic dietary practices to reduce one's BMI. Thus, by exploring relationship between BMI and SE, it may lay groundwork to shed light on ethnic and cultural variations in BMI and SE. Our results, however, suggests no correlation between SE and BMI. This finding is congruent with the finding that although there is increasing preoccupation with dietary in youngsters in Oman (Musaiger, 2011), the fat-phobia is generally not endorsed (Al-Adawi, Dorvlo, Viernes, Alexander, \& Al-Zakwani, 2012; Viernes et al., 2007) and as this study implies, this does not translate into variation in SE.

Stemming back from the romantic philosopher of the idea of noble savage, the rural community has often been portrayed as "pastoral, cohesive, friendly, and unhurried" (Yang \& Fetsch, 2007, p. 1) and unencumbered by the exigencies of the hassle and bustle of the urban setting. However, such portrayal has failed to gain empirical support. On one side, a study from Australia (Gordon \& Caltabiano, 1996) has indicated that rural adolescents scored higher on SE but a study among American children indicated thatrural/urban dichotomy is less pronounced in term of SE (Yang \& Fetsch, 2007). In another study in the American population, economic status appears to be related to SE rather than urban-rural residency (Housley et al., 1987). A study from Australia indicates that urban-rural residency has little bearing on SE but the presence of risk-taking trait and sedentary lifestyle are contributing factors to the direction of SE. There is dearth of studies examining the relationship between SE and urban-rural dichotomy among Arabic speaking populations. This study suggests strong correlation between SE and urban/rural residence with rural Omanis scoring higher in SE. 


\section{Limitations}

This study was limited by the fact that only gender, age, body mass index and place of residency were explored. Future studies could also include other factors that could contribute to SE such as socioeconomic status and academic and extra-curricular performance. Secondly, this study focused only on the age group of 15-17. Future studies could include wide age group variations in order to render the effect of age more meaningful. Thirdly, the concept of SE is likely to hinge on socio-cultural influences. Many studies have indicated that concept of SE is related to whether one belongs to an individualist or a collectivist society (Diener \& Marissa Diener, 2009). The present study was not equipped to decipher such confounding variables. Finally, the place of residence, operationalized here as urban-rural dichotomy, is difficult to define. In developing countries, urban area might be amalgamation of rural entity in a phenomenon known as "ruralisation of urban setting" (Bayat \& Denis, 2000). In Oman, previous studies have explore health trend in rural areas but such entity was ill-defined (Deleu, Khan, \& Al Shehab, 2002). Some studies tend to equate rural with lack of development which is not case for Oman. The discovery of oil has triggered economic growth which has rendered horizontal economic growth in all regions of the country (Al-Adawi, 2006a). Future studies ought to operationalize what constitute rural or urban. The study also did not survey the students attending private school which is different from the present public or government run schools in Oman. Parallel survey of this demographically diverse and internationally oriented population is suggested for future studies as a potentially valuable source of comparative data.

\section{Conclusion}

This study has explored the link between self-esteem (SE) and gender, age, body mass index and place of residence. Rosenberg Self-esteem Scale was used to tap into SE of teenagers of Oman. Female gender, rural residence, and different age group were significantly related to high SE but not BMI. To our knowledge, this is the first study to examine SE among national representative youth of Oman. Within the background of existing literature, this study is congruent with the previous observations that different ethnicities have different correlates of SE. This, in turn, suggests sociocultural or ecological factors play a substantial role in the expression of SE.

\section{References}

Abdel-Khalek, A. M., Korayem, A. S., \& El-Nayal, M. A. (2012). Self-esteem among college students from four Arab countries. Psychological Reports, 110(1), 297-303.

Akande, A. (1993). Sex differences in preferences for ideal female body shape. Health care for women international, 14(3), $249-259$.

Al-Adawi, S. (2006a). Adolescence in Oman. In J. J. Arnett (Ed.), International encyclopedia of adolescence: A historical and cultural survey of young people around the world (2 Volume Set) (pp. 713-728). New York: Routledge.

Al-Adawi, S. (2006b). Emergence of diseases of affluence in Oman: Where do they feature in the health research agenda? Sultan Qaboos University Medical Journal, 6(2), 3-9.

Al-Adawi, S., Dorvlo, A. S., Burke, D. T., Al-Bahlani, S., Martin, R. G., \& Al-Ismaily, S. (2002). Presence and severity of anorexia and bulimia among male and female Omani and non-Omani adolescents. Journal of the American Academy of Child \& Adolescent Psychiatry, 41(9), 1124-1130.

Al-Adawi, S., Dorvlo, A. S., Viernes, N., Alexander, P. C., \& Al-Zakwani, I. (2012). Is the diagnostic prototype for anorexia nervosa universal? Evidence from the Middle East and implications for ICD-11. Arab Journal of Psychiatry, 23(Suppl.), $42-50$.

Al-Adawi, S., Jaju, S., Al-Zakwani, I., \& Dorvlo, A. S. (2011). Culture to culture: Fat-phobia and somatization. In Handbook of behaviour, food and nutrition (pp. 1457-1473). New York: Springer. 
Aldaqal, S. M., \& Sehlo, M. G. (2013). Self-esteem and quality of life in adolescents with extreme obesity in Saudi Arabia: The effect of weight loss after laparoscopic sleeve gastrectomy. General Hospital Psychiatry, 35(3), 259-264.

Al-Fayez, G. A., Ohaeri, J. U., \& Gado, O. M. (2012). Prevalence of physical, psychological, and sexual abuse among a nationwide sample of Arab high school students: Association with family characteristics, anxiety, depression, self-esteem, and quality of life. Social Psychiatry and Psychiatric Epidemiology, 47(1), 53-66.

Al-Lamki, S. M. (2002). Higher education in the Sultanate of Oman: The challenge of access, equity and privatization. Journal of Higher Education Policy and Management, 24(1), 75-86.

Baumeister, R. F., Campbell, J. D., Krueger, J. I., \& Vohs, K. D. (2003). Does high self-esteem cause better performance, interpersonal success, happiness, or healthier lifestyles? Psychological Science in the Public Interest, 4(1), 1-44.

Bayat, A., \& Denis, E. (2000). Who is afraid of ashwaiyyat? Urban change and politics in Egypt. Environment and Urbanization, 12(2), 185-199.

Berry, J. W., Phinney, J. S., Sam, D. L., \& Vedder, P. E. (2006). Immigrant youth in cultural transition: Acculturation, identity, and adaptation across national contexts. London: Lawrence Erlbaum Associates Publishers.

Bleidorn, W., Arslan, R. C., Denissen, J. J., Rentfrow, P. J., Gebauer, J. E., Potter, J., \& Gosling, S. D. (2016). Age and gender differences in self-esteem - A cross-cultural window. Journal of Personality and Social Psychology, 111(3), 396-410.

Bleidorn, W., Buyukcan-Tetik, A., Schwaba, T., Van Scheppingen, M. A., Denissen, J. J., \& Finkenauer, C. (2016). Stability and change in self-esteem during the transition to parenthood. Social Psychological and Personality Science, 7(6), 560-569.

Choi, E., \& Choi, I. (2016). The associations between body dissatisfaction, body figure, self-esteem, and depressed mood in adolescents in the United States and Korea: A moderated mediation analysis. Journal of Adolescence, 53, 249-259.

Cole, T. J., Bellizzi, M. C., Flegal, K. M., \& Dietz, W. H. (2000). Establishing a standard definition for child overweight and obesity worldwide: international survey. BMJ, 320(7244), 1240-1243.

Corruccini, R. S., \& Kaul, S. S. (1983). Part 3: The epidemiological transition and anthropology of minor chronic non-infectious diseases. Medical Anthropology, 7(3), 36-50.

Damon, W., \& Hart, D. (1982). The development of self-understanding from infancy through adolescence. Child Development, 53(4), 841-864.

Deleu, D., Khan, M. A., \& Al Shehab, T. A. (2002). Prevalence and clinical characteristics of headache in a rural community in Oman. Headache, 42(10), 963-973.

Diener, E., \& Marissa Diener, M. (2009). Cross-cultural correlates of life satisfaction and self-esteem. In Culture and well-being (pp. 71-91). Netherlands: Springer.

Fromm, E. (1939). Selfishness and self-love. Psychiatry, 2(4), 507-523.

Furnham, A., Badmin, N., \& Sneade, I. (2002). Body image dissatisfaction: Gender differences in eating attitudes, self-esteem, and reasons for exercise. Journal of Psychology, 136(6), 581-596.

Gooding, P., Tarrier, N., Dunn, G., Shaw, J., Awenat, Y., Ulph, F., \& Pratt, D. (2015). The moderating effects of coping and self-esteem on the relationship between defeat, entrapment and suicidality in a sample of prisoners at high risk of suicide. European Psychiatry, 30(8), 988-994.

Gordon, W. R., \& Caltabiano, M. L. (1996). Urban-rural differences in adolescent self-esteem, leisure boredom, and sensation-seeking as predictors of leisure-time usage and satisfaction. Adolescence, 31(124), 883-901.

Goujon, A., Weber, D., \& Loichinger, E. (2016). Demographic profile of the Arab region: Realizing the demographic dividend. United Nations. Beirut. Retrieved from https://www.unescwa.org/sites/www. unescwa.org/files/publications/files/demographic-profile-arab-region-2015-english.pdf

Heine, S. J., Lehman, D. R., Markus, H. R., \& Kitayama, S. (1999). Is there a universal need for positive self-regard? Psychological Review, 106(4), 766-794.

Hesse-Biber, S., \& Am I, T. E. Y. (1996). The cult of thinness and the commercialisation of identity. Oxford: Oxford University Press.

Housley, K., Martin, S., Mc Coy, H., Greenhouse, P., Stigger, F., \& Chopin, L. (1987). Self-esteem of adolescent females as related to race, economic status, and area of residence. Perceptual and Motor Skills, 64(2), 559-566.

Hudson, N. W., \& Fraley, R. C. (2016). Do people's desires to change their personality traits vary with age? An examination of trait change goals across adulthood. Social Psychological and Personality Science, 7(8), 847-856.

International Conference on Challenges of Urbanization in GCC Countries. (2014). Oman News Agency. Retrieved October 17, 2014 from http://search.proquest.com/docview/1509233728?accountid=27575 
Islam, M. M. (2014). Factors influencing the academic performance of undergraduate students in Sultan Qaboos University in Oman. Journal of Emerging Trends in Educational Research and Policy Studies, 5(4), 396-404.

Kayano, M., Yoshiuchi, K., Al-Adawi, S., Viernes, N., Dorvlo, A. S., Kumano, H., ... \& Akabayashi, A. (2008). Eating attitudes and body dissatisfaction in adolescents: Cross-cultural study. Psychiatry and Clinical Neurosciences, 62(1), 17-25.

Khan, F., \& Fernandez-Carag, M. (2016). Gender parity and equality in the Sultanate of Oman: A case in education for the gulf cooperation council countries. The International Journal of Social Quality, 6(1), 67-86.

Kiviruusu, O., Konttinen, H., Huurre, T., Aro, H., Marttunen, M., \& Haukkala, A. (2016). Self-esteem and body mass index from adolescence to mid-adulthood. A 26-year follow-up. International Journal of Behavioral Medicine, 23(3), 355-363.

Kling, K. C., Hyde, J. S., Showers, C. J., \& Buswell, B. N. (1999). Gender differences in self-esteem: A meta-analysis. Psychological Bulletin, 125, 470-500. Retrieved from http://dx.doi.org/10.1037/0033-2909.125.4.470

Konttinen, H., Kiviruusu, O., Huurre, T., Haukkala, A., Aro, H., \& Marttunen, M. (2014). Longitudinal associations between depressive symptoms and body mass index in a 20-year follow-up. International Journal of Obesity, 38(5), 668-674. doi:10.1038/ijo.2013.151

Kutáč, P. (2015). Inter-daily variability in body composition among young men. Journal of Physiological Anthropology, 34(1), 32 doi:10.1186/s40101-015-0070-6

Lee, T. H., Kim, T. H., Kim, W., \& Park, E. C. (2016). Effects of difference in self-esteem between spouses on depressive symptom: Result from a data nationally representative of South Korean. Psychiatry Research, 246, 623-628.

Malik, V. S., Willett, W. C., \& Hu, F. B. (2013). Global obesity: Trends, risk factors and policy implications. Nature Reviews Endocrinology, 9(1), 13-27.

Ministry of Education. (2017). Educational portal-Ministry of Education-Oman. Retrieved from http:/home.moe.gov.om/english/module.php?module=pages-showpage \&CatID=1\&ID=247

Mulder, M. B. (1998). The demographic transition: Are we any closer to an evolutionary explanation? Trends in Ecology \& Evolution, 13(7), 266-270.

Musaiger, A. O. (2004). Overweight and obesity in the Eastern Mediterranean Region: Can we control it? Eastern Mediterranean Health Journal, 10, 789-793.

Musaiger, A. O. (2011). Overweight and obesity in eastern mediterranean region: Prevalence and possible causes. Journal of Obesity, 2011(6), 407237. doi:10.1155/2011/407237

Musaiger, A. O., Al-Mannai, M., Tayyem, R., Al-Lalla, O., Ali, E. Y, Kalam, F., Benhamed, M. M., Saghir, S., Halahleh, I., Djoudi, Z., \& Chirane, M. (2013). Risk of disordered eating attitudes among adolescents in seven Arab countries by gender and obesity: A cross-cultural study. Appetite, 60(1), 162-167.

Nagar, S., Sharma, S., \& Chopra, G. (2008). Self esteem among rural adolescent girls in Kangra District of Himachal Pradesh. The Anthropologist, 10(2), 151-154. doi:10.1080/09720073.2008.11891041

Nettleton, S. (2013). The sociology of health and illness (3rd ed.). New York: Polity Press.

Ogihara, Y., Uchida, Y., \& Kusumi, T. (2016). Losing confidence over time: Temporal changes in self-esteem among older children and early adolescents in Japan, 1999-2006. SAGE Open, 6(3), 2158244016666606.

Omran, A. R. (Dec. 1, 2005). The epidemiologic transition: A theory of the epidemiology of population change. Milbank Quarterly, 83(4), 731-757.

Peen, J., Schoevers, R. A., Beekman, A. T., \& Dekker, J. (2010). The current status of urban-rural differences in psychiatric disorders. Acta Psychiatrica Scandinavica, 121(2), 84-93.

Piyavhatkul, N., Aroonpongpaisal, S., Patjanasoontorn, N., Rongbutsri, S., Maneeganondh, S., \& Pimpanit, W. (2011). Validity and reliability of the Rosenberg Self-Esteem Scale-Thai version as compared to the Self-Esteem Visual Analog Scale. Journal of the Medical Association of Thailand, 94(7), 857-862.

Popenoe, R. (2012). Feeding desire: Fatness, beauty and sexuality among a Saharan people. New York: Routledge.

Robins, R. W., Trzesniewski, K. H., Tracy, J. L., Gosling, S. D., \& Potter, J. (2002). Global self-esteem across the life span. Psychology and Aging, 17(3), 423-434.

Rosenberg, M. (1965). Society and the adolescent self-image. Princeton, NJ: Princeton University Press.

Sambidge, A. (2014). Oman's population passes 4 million mark-Politics \& economics-ArabianBusiness.com. Retrieved $\begin{array}{llll}\text { September } & 30, & 2017 & \text { from }\end{array}$ http://www.arabianbusiness.com/oman-s-population-passes-4-million-mark-547779.html\#.VzwSiOQwCxY

Schmitt, D. P., \& Allik, J. (2005). Simultaneous administration of the Rosenberg Self-Esteem Scale in 53 nations: Exploring the universal and culture-specific features of global self-esteem. Journal of Personality and Social Psychology, 89(4), 623-642. 
Taormina, R. J., \& Gao, J. H. (2013). Maslow and the motivation hierarchy: Measuring satisfaction of the needs. American Journal of Psychology, 126(2), 155-177.

United Nations Development Programme. (2016). Oman. Human Development Reports 2016. Retrieved from http://hdr.undp.org/en/countries/profiles/OMN

Viernes, N., Zaidan, Z. A., Dorvlo, A. S., Kayano, M., Yoishiuchi, K., Kumano, H., ... \& Al-Adawi, S. (2007). Tendency toward deliberate food restriction, fear of fatness and somatic attribution in cross-cultural samples. Eating Behaviors, 8(3), 407-417.

Wild, L. G., Flisher, A. J., Bhana, A., \& Lombard, C. (2004). Associations among adolescent risk behaviours and self-esteem in six domains. Journal of Child Psychology and Psychiatry, 45(8), 1454-1467.

World Bank. World Development Indicators. (2017). Oman. Retrieved from http://databank.worldbank.org/-data/reports.aspx? source=2\&country=OMN

Yang, R. K., \& Fetsch, R. J. (2007). The self-esteem of rural children. Journal of Research in Rural Education, 22(5), 22-25.

Zuckerman, M., Li, C., \& Hall, J. A. (2016). When men and women differ in self-esteem and when they don't: A meta-analysis. Journal of Research in Personality, 64, 34-51. 